\title{
Modelling diagnosis of heavy metal (copper) transport in an estuary
}

\author{
Wen-Cheng Liu ${ }^{\mathrm{a}, *}$, Shu-Wei Chang ${ }^{\mathrm{b}}$, Kuo-Tung Jiann ${ }^{\mathrm{c}}$, \\ Liang-Saw Wen ${ }^{\mathrm{d}}$, Kon-Kee Liu ${ }^{\mathrm{b}}$ \\ a Department of Civil and Disaster Prevention Engineering, National United University, 36003, Taiwan \\ ${ }^{\mathrm{b}}$ Institute of Hydrological Sciences, National Central University, Jhongli 32001, Taiwan \\ ${ }^{\mathrm{c}}$ National Center for Ocean Research, P.O. Box 23-13, 10617 Taipei, Taiwan \\ d Institute of Oceanography, National Taiwan University, 10617 Taipei, Taiwan
}

Received 13 April 2007; received in revised form 30 July 2007; accepted 8 August 2007

Available online 19 September 2007

\begin{abstract}
A vertical (laterally-averaged) two-dimensional heavy metal transport model was developed to simulate the fluxes of copper in the Danshuei River estuarine system. The toxic model was incorporated into the hydrodynamic, the salt transport and the sediment transport modules. The model has been validated with observed time series data of water surface elevation, current, salinity, and suspended sediment concentrations in 2001 and 2002. An exponential relationship was established to relate variation in partition coefficient of copper to salinity and suspended sediment concentrations in the Danshuei River estuary. Comparisons of the total, dissolved, and particulate copper concentrations calculated by the numerical model and field data along the Danshuei River-Tahan Stream show good agreement. It is noteworthy that the model requires a point source of total copper with the strength of $250 \mathrm{~kg} / \mathrm{day}$ to account for the observed persistently high total copper concentration near Hsin-Hai Bridge in the Tahan Stream, about 24km upriver from the river mouth. The huge garbage dump site near the Hsin-Hai Bridge is likely the source of heavy metal pollution.

The validated model was then applied to investigate the tidally averaged salinity distributions, residual circulation, suspended sediment, and total copper concentrations under low flow condition. The residual circulation is characterized by the upriver movement of denser saline water in the lower layer and the downriver movement of fresher water in the upper layer. The circulation pattern is driven by the longitudinal gradient of salinity distribution. The residual circulation occurs in the deep channel of KuanDu Bridge and Taipei Bridge. Under low flow condition, the limits of salt intrusion are located at Hsin-Hai Bridge. The tidallyaveraged sediment concentration distribution exhibits a local maximum concentration around the null point in the Danshuei RiverTahan Stream. A local maximum of total copper concentration, which is nearly as high as that near the point source, occurs around the null point, which is potentially a hot spot of heavy metal accumulation.
\end{abstract}

(C) 2007 Published by Elsevier B.V.

Keywords: Copper; Modelling; Danshuei River estuary; Heavy metal transport; Hydrodynamic; Salinity; Residual circulation; Suspended sediment

\section{Introduction}

Heavy metal pollution has drawn increasing attention worldwide due to a dramatic increase of anthropogenic

\footnotetext{
* Corresponding author. Tel.: +886 37381674 ; fax: +886 37326567

E-mail address: wcliu@nuu.edu.tw (W.-C. Liu).
}

heavy metal to the ecosystems through air, water, and soils (Fang et al., 2000; He et al., 2001; Adamo et al., 2002; Woitke et al., 2003). Heavy metals in sediments represent a combination effect of chemical, biological and physical processes occurring in fluvial, estuarine, and coastal environments. Surface sediments integrate these changes that occur in the water column and act both as a repository 
and source of suspended materials. Spatial variations of heavy metals in the surface sediments are the results of these processes (Windom et al., 1989; Birch and Taylor, 1999; Lin et al., 2002; Huang and Lin, 2003). In addition, anthropogenic disturbance to the environment often registered significant footprints in sediments.

Heavy metals generally exist in two phases in estuarine waters, i.e., in the dissolved phase in the water column and in the particulate phase adsorbed on the sediments. The behavior of heavy metals in the aquatic environment is strongly influenced by adsorption to organic and inorganic particles. The dissolved fraction of the heavy metals may be transported through the water column via the processes of advection and dispersion, while the particulate fraction may be transported with the sediments, which are governed by sediment dynamics. The partition of heavy metals between the dissolved and adsorbed particulate phases depends on the physical and chemical characteristics of the suspended particles as well as various ambient conditions, such as: salinity, $\mathrm{pH}$, the types and concentrations of dissolved organic matter (Bourg, 1987; Turner and Millward, 1994; Turner et al., 2001; Turner and Millward, 2002; Wu et al., 2005).

Fine sediments, acting as a source (or sink) for the organic chemical and heavy metals entering (or leaving) the water column with sediments contaminated by the heavy metals, pose a potential threat to the aquatic environment. Resuspension of contaminated bed sediments caused by strong tidal currents may release a significant amount of heavy metals into the water column, and this desorption of contaminants from their particulate phase can have a pronounced impact on the aquatic environment and ecosystem. Numerical models provide a valuable tool for predicting the fate and transport of heavy metals in estuarine and wetland environments and are increasingly used for such hydro-environmental management studies of estuarine waters (Chen et al., 1996; Lung and Light, 1996; Ng et al., 1996; Mwanuzi and Smedt, 1999; Wu et al., 2005; Hartnett et al., 2006; Zagar et al., 2006).

During the past several decades, many numerical models were developed to simulate the behaviors of estuaries using one-dimensional, two dimensional, or three-dimensional numerical models. Although the fully three-dimensional models was often used, the laterally averaged model was an efficient and economic tool to study estuarine dynamics in a two-dimensional view of narrow estuaries, Physically, this kind of model was able to describe major estuarine phenomena, since tides, tidal current, salt, sediment and heavy metal transport, as well as ecological processes, were dominated by bathymetric variations which occur mainly along the channel. Therefore, laterally averaged models have been widely applied to study estuarine dynamics. In this paper a twodimensional, laterally-averaged finite difference model of heavy metal transport was developed by incorporating the hydrodynamic, the salt transport and the sediment transport modules which were developed earlier (Hsu et al., 1999; Liu et al., 2001a, 2002). The model was applied to simulate the distribution of total copper concentration, which is partitioned into the dissolved and the particulate phases, in the Danshuei River estuarine system, which drains the Taipei metropolitan area, the most populated region in Taiwan. The model predictions and measured data were compared to evaluate the model reliability.

\section{The Danshuei River estuarine system}

The Danshuei River estuary, located on the outskirts of Taipei, is the largest estuary in northern Taiwan. The Danshuei River is formed by the confluence of the Tahan Stream, Hsintien Stream and Keelung River (Fig. 1). The Tahan Stream joints Hsintien Stream at Wan-Hwa. The river then combined with the Keelung River at the Kuan-Du. The segment of the estuary from Wan-Hwa to the estuarine mouth is called the Danshuei River. The downstream portions of all three tributaries are influenced by tide, and subjected to sea water intrusion. The upriver reaches are affected by daily varying freshwater discharges. Its drainage area encompasses $2728 \mathrm{~km}^{2}$ with a total channel length of $327.6 \mathrm{~km}$. The major portion of the estuarine system, upriver of KuanDu (Fig. 1), lies within the Taipei basin, while the stretch downriver is confined by high mountains on both sides. Because of the presence of mountains and narrowness of the river, there is no significant wind-induced current. Except the occasional storm surges induced by hurricanes, the major forcing mechanisms of the barotropic flows are astronomical tide at the river mouth and river discharges at upriver ends. Semi-diurnal tides are the principal tidal constituents, with a mean tidal range of $2.22 \mathrm{~m}$ and a spring tidal range of $3.1 \mathrm{~m}$. The average river discharges are $62.1 \mathrm{~m}^{3} / \mathrm{s}, 72.7 \mathrm{~m}^{3} / \mathrm{s}$, and $26.1 \mathrm{~m}^{3} / \mathrm{s}$, respectively, in the Tahan Stream, Hsintien Stream and Keelung River. In addition to the barotropic flows forced by tide and river discharges, the baroclinic flow forced by sea water intrusion is another important transport mechanism in the Danshuei River estuarine system (Liu et al., 2001a,b, 2004). Salinity varies on the intra-tidal time scale in response to the ebb and flood tidal flows as well as in response to changing freshwater inflows (Liu et al., 2007). According the classification given by Dyer (1997), the Danshuei River estuarine system was classified as mesotidal and partially mixed estuary. 


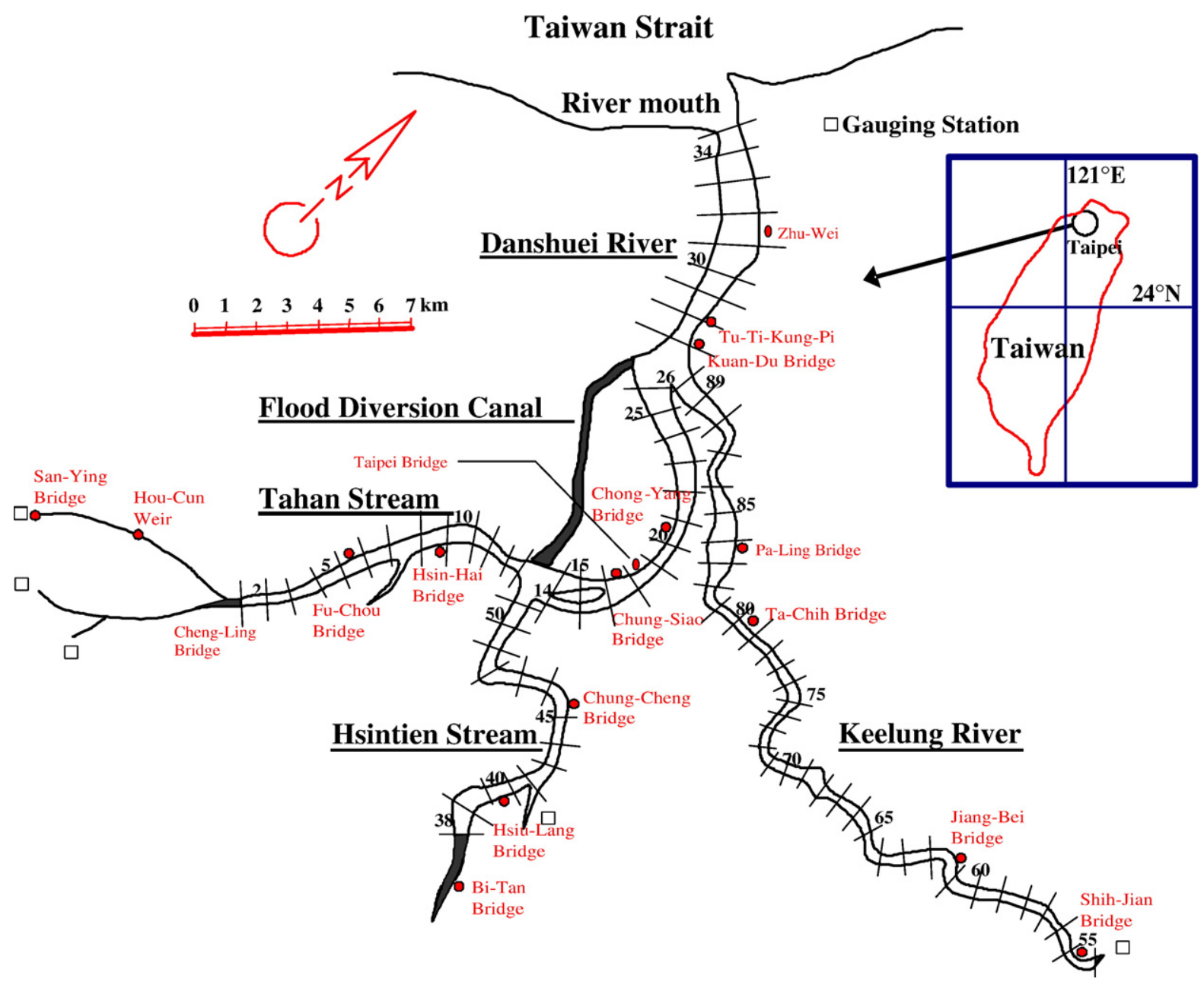

Fig. 1. Map of the Danshuei River estuary and the model segments (Lines cutting across the river are model transects at $1.0 \mathrm{~km}$ interval; numbers are model segment numbers.).

Six million people, over a quarter of Taiwan's entire population, reside in the catchment area of the Danshuei River system. The Danshuei River estuary receives untreated domestic discharge and both treated and untreated industrial effluents from its tributaries; it is heavily polluted by trace metals and organic materials (Jeng and Han, 1994). Approximately $1.79 \times 10^{6} \mathrm{~m}^{3} /$ day of mostly untreated domestic sewage enters the Danshuei River system (Wu, 1997), which contributes along with waste effluent from industries, to hypoxia in the upper estuary (Fang, 2000; Wang et al., 2007).

The observational data reported by the Environmental Protection Administration (EPA), Taiwan were analyzed to comprehend the distribution of copper, an important heavy metal pollutant (Jiann et al., 2005). Fig. 2 presents the mean and standard deviation of total copper concentrations in the Danshuei River-Tahan
Stream. The distances from Danshuei River mouth for specific estuarine locations are listed in Table 1. The high standard deviation values presented in the figure shows that the large variations exhibit at the measured locations. It reveals a pronounced high copper concentration at the Hsin-Hai Bridge, indicating a point source pollution, which is probably caused by the nearby garbage dump. The strength of the point source is to be estimated for the fist time by the modelling exercise.

\section{Description of the model}

To calculate the movement of water flow, salinity transport, suspended sediment distribution, and heavy metal transport processes in the Danshuei River estuary, the timedependent, three-dimensional equations of motion and the equation of mass balance are first integrated laterally to 


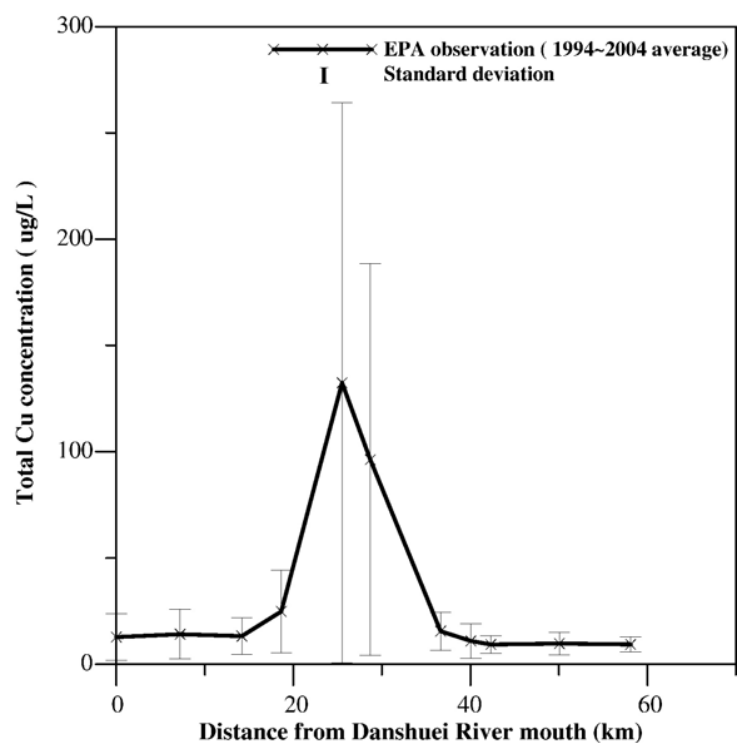

Fig. 2. Mean and standard deviation of total copper concentrations observed between 1994 and 2004 as reported by EPA of Taiwan.

obtain two-dimensional equations. Next, the two-dimensional equations are layer-integrated, and the resulting equations for each layer are written in finite difference forms. The finite difference equations are then solved numerically with prescribed initial and boundary conditions. The numerical computation yields the time-varying tidal height, current, salinity, suspended sediment concentration, and copper distributions throughout the estuary.

\subsection{Hydrodynamic model}

The hydrodynamic model used to predict the water surface elevations, longitudinal and vertical velocities is based on the governing equations of fluid flow. Generally, the flow was assumed to be isothermal and the vertical acceleration was assumed to be small compared to the gravitational acceleration, yielding a hydrostatic pressure distribution. Tidal forcing is prescribed at the downstream boundary, whereas the flow rates are imposed at the tidal limits at upstream boundaries. In addition to the momentum and continuity equations, the model also solves transport equation for salt and an equation of state to include the baroclinic effects. The turbulent shear stresses are equated to the wind stress on the free-surface and to the bottom friction on the bed, with both stresses being expressed using a quadratic friction law. Further details of the governing equations used in the model are given in Hsu et al. (1999).

\subsection{Sediment transport model}

The following advection-diffusion, partial differential equation is used to describe the suspended sediment transport processes:

$$
\begin{gathered}
\frac{\partial(B m)}{\partial t}+\frac{\partial(u B m)}{\partial x}+\frac{\partial\left[\left(w-W_{s}\right) B m\right]}{\partial z}=\frac{\partial}{\partial x}\left(K_{x} B \frac{\partial m}{\partial x}\right) \\
+\frac{\partial}{\partial z}\left(K_{z} B \frac{\partial m}{\partial x}\right)-B d+B r+q_{p} m_{T}
\end{gathered}
$$

where $t$ is time, $x$ and $z$ are longitudinal and vertical coordinates, respectively. $m$ is the suspended sediment concentration, $B$ is the river width as a function of $x$ and $z$, $u$ and $w$ are the velocity components in the $x$ and $z$ directions, respectively, $W_{s}$ is the apparent sediment settling velocity, $d$ is sediment deposition rate, $r$ is sediment resuspension rate, $q_{p}$ is tributary inflow through unit area of $x-z$ plane, $m_{T}$ is the sediment concentration of tributary flow, $K_{x}$ and $K_{z}$ are turbulent diffusion coefficients in the $x$ and $z$ directions, respectively. The deposition rate, $d$, and the resuspension rate, $r$, are zero except at the bottom interface.

The Munk-Anderson type formulations are used to calculate the vertical turbulent diffusion coefficient, $K_{z}$. The model used constant values for $K_{x}$ and it is adjusted,

Table 1

\begin{tabular}{|c|c|c|c|c|c|c|}
\hline Station & $\begin{array}{l}\text { River mouth } \\
\text { (Danshuei River) }\end{array}$ & $\begin{array}{l}\text { Kuan-Du Bridge } \\
\text { (Danshuei River) }\end{array}$ & $\begin{array}{l}\text { Chong-Yang Bridge } \\
\text { (Danshuei River) }\end{array}$ & $\begin{array}{l}\text { Taipei Bridge } \\
\text { (Danshuei River) }\end{array}$ & $\begin{array}{l}\text { Chung-Siao Bridge } \\
\text { (Danshuei River) }\end{array}$ & $\begin{array}{l}\text { Hsin-Hai Bridge } \\
\text { (Tahan Stream) }\end{array}$ \\
\hline $\begin{array}{l}\text { Distance from } \\
\text { Danshuei River } \\
\text { mouth }(\mathrm{km})\end{array}$ & 0.0 & 7.30 & 14.18 & 16.76 & 18.63 & 25.45 \\
\hline Station & $\begin{array}{l}\text { Fu-Chou Bridge } \\
\text { (Tahan Stream) }\end{array}$ & $\begin{array}{l}\text { Chung-Cheng Bridge } \\
\text { (Hsintien Stream) }\end{array}$ & $\begin{array}{l}\text { Pa-Ling Bridge } \\
\text { (Keelung River) }\end{array}$ & $\begin{array}{l}\text { Ta-Chih Bridge } \\
\text { (Keelung River) }\end{array}$ & $\begin{array}{l}\text { Jiang-Bei Bridge } \\
\text { (Keelung River) }\end{array}$ & \\
\hline $\begin{array}{l}\text { Distance from } \\
\text { Danshuei River } \\
\text { mouth }(\mathrm{km})\end{array}$ & 26.69 & 27.48 & 14.77 & 19.32 & 38.62 & \\
\hline
\end{tabular}

Distances from Danshuei River mouth for specific estuarine locations. 
within the range of $10^{4}$ to $10^{6} \mathrm{~cm}^{2} / \mathrm{s}$, through hydrodynamic model calibration (Hsu et al., 1999).

\subsection{The erosion model}

Erodibility of a cohesive bed is driven by shear, but also depends on the bottom cohesive nature, which in turn depends, in a poorly understood way, on clay mineralogy and on the geochemistry and microbiological processes occurring in the bottom. Some authors argued that it should also depend on the salinity (Hayter and Mehta, 1986). However, no dependency laws have not yet been developed.

The erosion algorithm used in this work is based on the classical approach of Partheniades (1965). Erosion occurs when the bed shear stress exceeds the threshold of erosion. The flux of eroded matter is given by:

$r=M\left(\frac{\tau}{\tau_{E}}-1\right)$ for $\tau>\tau_{E}$

$r=0$ for $\tau \leq \tau_{E}$

where $\tau$ is the bed shear stress, $\tau_{E}$ is the critical shear stress for erosion and $M$ is the erosion constant.

\subsection{The deposition model}

The deposition algorithm, like the erosion algorithm, is based on the assumption that deposition and erosion never occur simultaneously. An algorithm was first proposed by Krone (1962) and later modified by Odd and Owen (1972). The deposition rate is calculated as the product of the settling flux and the probability of a particle to remain on the bed:

$d=m_{b} W_{s}\left(1-\frac{\tau}{\tau_{D}}\right)$ for $\tau<\tau_{D}$

$d=0$ for $\tau \geq \tau_{D}$

where $\tau_{D}$ is the critical shear stress for deposition and $m_{b}$ is the sediment concentration at the bottom layer.

\subsection{Heavy metal transport model}

The total heavy metal transport model depends on the mass balance equation is given by:

$$
\begin{aligned}
\frac{\partial(B C)}{\partial t} & +\frac{\partial(u B C)}{\partial x}+\frac{\partial(w B C)}{\partial z} \\
& -\frac{\partial\left(W_{s} B C_{p}\right)}{\partial z}=\frac{\partial}{\partial x}\left(K_{x} B \frac{\partial C}{\partial x}\right)+\frac{\partial}{\partial z}\left(K_{z} B \frac{\partial C}{\partial x}\right) \\
& -\alpha d+\beta r+q_{p} C_{t}
\end{aligned}
$$

where $C$ is the total heavy metal concentration, $C_{t}$ is the total heavy metal concentration of tributary flow; $\beta=$ $C_{b o} / m_{b}, C_{b o}$ is the total heavy metal concentration in the sediment bed; $\alpha=C_{b p} / m_{b}, C_{b p}$ is the particulate heavy metal concentration at the bottom layer of the water column.

\subsection{Partition coefficient}

Heavy metals typically exist in both the dissolved and the particulate phases in estuaries. The distribution between these two phases can be described by a partition coefficient, $K_{d}$, defined as:

$K_{d}=\frac{\left(\frac{C_{p}}{m}\right)}{C_{d}}$

$C=C_{d}+C_{p}$

where $C_{d}$ is the concentration of heavy metal copper dissolved in the water column, $C_{p}$ is absorbed particulate copper concentration.

\subsection{Heavy metal in sediment bed model}

The settling and deposition of sediment-sorbed solutes are the major removal mechanisms for contaminants in the overlying waters, while resuspension of contaminated sediment together with desorption processes serve as major sources of contaminants. The inventory of mobilizable heavy metal in the sediment bed can be expressed as:

$\frac{\partial\left(H B C_{b o}\right)}{\partial t}=B \alpha d-B \beta r$

where $H$ is the active depth of sediment bed which is assumed to be $0.5 \mathrm{~m}$ (Van Maldegem et al., 1993; Mwanuzi and Smedt, 1999).

\subsection{Numerical methods}

The system is solved suing the finite difference method with a uniform grid of spatially staggered variables. The staggered gird structure, also used in many other models, permits easy application of boundary conditions and evaluation of the dominant pressure gradient force without interpolation (Blumberg, 1977). Since the vertical two-dimensional hydrodynamic model does not included the Coriolis term, a two-time level scheme is used to approximate the time derivate terms in the equation. This avoids the problem of time-stem splitting which is often associated with a three-time level scheme. 


\section{Model calibration and verification}

\subsection{Hydrodynamics}

The hydrodynamic model is supplied with data describing the geometry of the Danshuei River estuarine system. The geometry in the vertical two-dimensional model is represented by width at each layer at the center of each grid cell. A field survey in 2001 by Taiwan Water Resources Agency collected the crosssectional profiles at about $0.5 \mathrm{~km}$ interval along the tidal portion of the river. These profiles were used to schematize the river system. The three branches are divided into 33,14, and 37 segments, respectively, with a uniform segment length of $1.0 \mathrm{~km}$. The vertical layer thickness is $1 \mathrm{~m}$ for all layers, except the surface layer, which is variable, with a thickness of $2 \mathrm{~m}$ at mean sea level. The maximum number of layers is 10 at the deepest section of the river.

The downstream boundary is located at the river mouth where the water surface elevation, high tide salinity and concentration are specified. The upstream boundaries are not influenced by the tide and beyond tidal limits in the tributaries and in the main stem. Therefore the daily freshwater discharges are specified and the salinity is assumed to be zero at these boundaries. The concentrations of suspended sediment and heavy metal are also specified at the upstream boundary conditions. The hydrodynamic model was also expanded to include the capability to simulate tributaries as well as the main stem of estuaries (Hsu et al., 1999). In implementing the numerical model to the estuarine system, Danshuei River and Tahan Stream were regarded as the main stem, while the Hsintien Stream and Keelung River were simulated as tributaries.

Manning's friction coefficient and the coefficients for turbulent diffusion terms are important calibration parameters affecting the calculation of surface elevation, current velocity and salinity distribution. Since tidal flow constitutes the major portion of energy in the Danshuei River estuary, the Manning's coefficient was adjusted by trial and error based on a comparison of the predicted tidal wave propagation with measured data.

The model was verified by simulating the measured data for the period of September 19, 2001 to September 30,2002 . Hourly measurements of water surface elevation at the river mouth and daily freshwater discharges upriver of tidal limits were used as boundary conditions. These conditions serve to investigate the model response to the interaction of tidal forcing and varying river discharges. Fig. 3 shows some segments of computed surface elevation, together with measured data. The distances from Danshuei River mouth for the locations are shown in Table 1. It shows that upriver stations (Hsin-Hai Bridge and Chung-Cheng Bridge) have a more conspicuous response to pulse of high freshwater discharge than downstream station (Tu-Ti-Kung-Pi and Taipei Bridge, shown in Fig. 1).

The Taiwan Water Resources Agency conducted the intensive field measurements on April 26, 2002. The current speed was measured at half-hour intervals by personnel on boats for a period of 13 daylight hours. Velocity data were taken with handheld current meters that measured current magnitude but not the direction. The data were recorded by hand, and "ebb or flood" direction was noted with visual observation. Except for the upriver transects close to tidal limits, the measurements were made at several depths for points in the transverse direction. To compare with the results of the vertical two-dimensional model, the data in the transverse direction were averaged to obtain the laterally-averaged values. Fig. 4 presents the comparison of the time series data of the longitudinal velocity on April 26, 2002. These results show that the streamwise flow velocity was reasonably well predicted by the numerical model for that day. It was also found that the flood tidal current is weaker with shorter duration than that the ebb tidal current in the estuary. This was attributed to the tidal asymmetry caused by the interaction between the incoming tide and river flow. Through the trial and error method, the calibrated model has the Manning's friction coefficient ranging from 0.032 to 0.026 in the Danshuei River-Tahan Stream, 0.015 for the Hsintien Stream, and from 0.023 to 0.016 for the Keelung River.

The mixing length concept was used to calculate eddy viscosity and diffusion coefficient in the vertical direction. The formulations similar to those proposed by Pritchard (1960) are used in the model. The time series data of salinity measured on 2001 were used to verify the constants in the formulation of vertical diffusion coefficient. Fig. 5 presents the comparison of computed and measured time-series salinity at the Kuan-Du Bridge. The results show that the model computed salinities agree well with the field observation in term of intra-tidal variation as well as the overall averaged level. It is noted that, as high freshwater discharges input from upriver boundaries, the salinity sharply decreases, such as for the peak in discharge occurring by 287.5 days in Fig. 5b. This phenomenon was well predicted by the model. The verified values of the longitudinal dispersion coefficients were $K_{x}=28 \times 10^{5} \mathrm{~cm}^{2} / \mathrm{s}$ for the Danshuei River-Tahan Stream, $K_{x}=3.5 \times 10^{5} \mathrm{~cm}^{2} / \mathrm{s}$ for the Hsintien Stream, and $K_{x}=5 \times 10^{4} \mathrm{~cm}^{2} / \mathrm{s}$ for the Keelung River. 

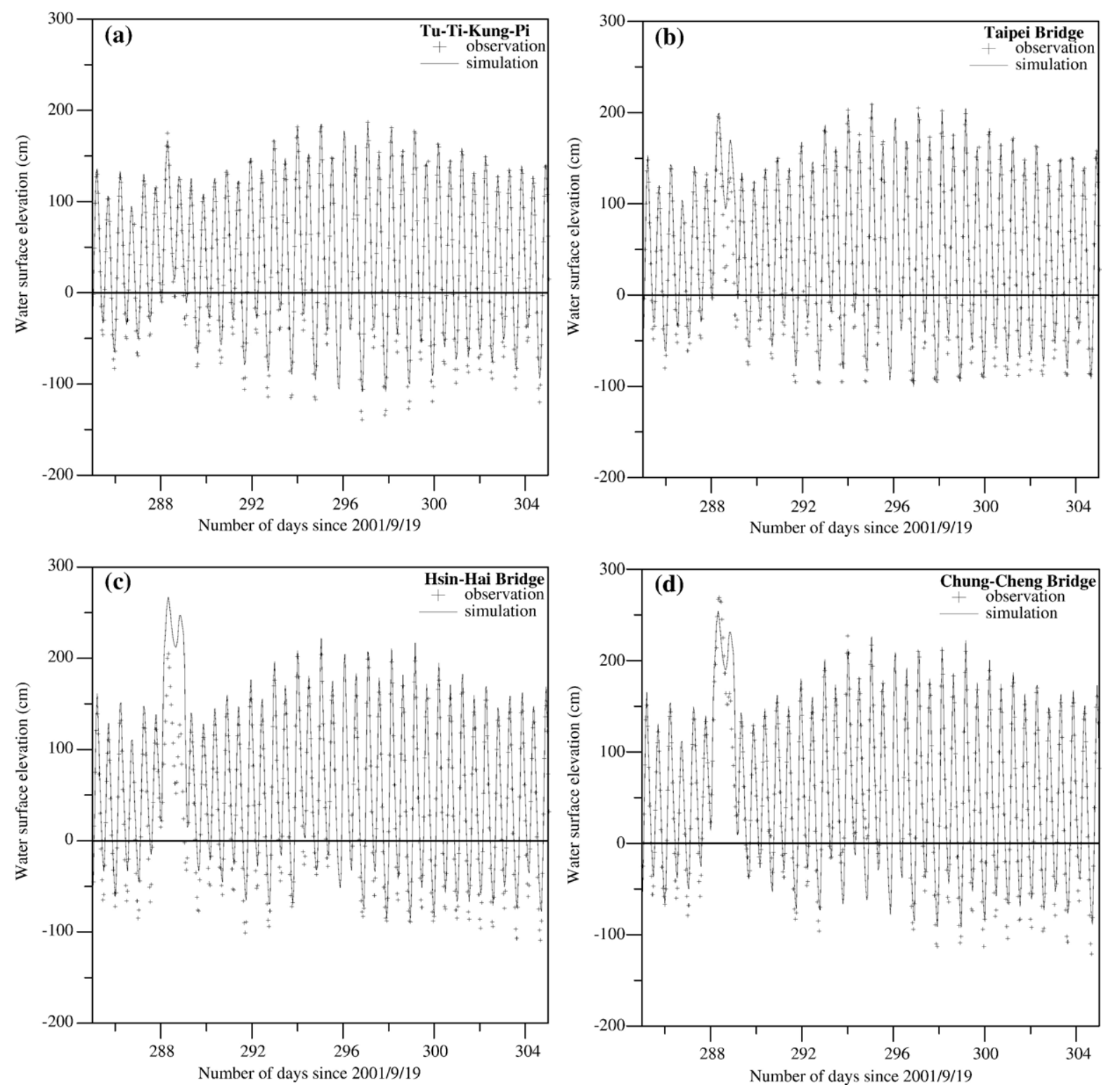

Fig. 3. Comparison of predicted and measured water surface elevation at (a) Tu-Ti-Kung-Pi, (b) Taipei Bridge, (c) Hsin-Hai Bridge, and (d) Chung-Cheng Bridge.

\subsection{Cohesive sediment transport}

Measurements of the suspended sediment concentrations in the Danshuei River estuarine system in 2002 were used to verify the cohesive sediment transport model. The field data were measured and provided by Hsu et al. (2003). The model was run for one-year simulation. The averaged settling velocity of $0.026 \mathrm{~cm} / \mathrm{s}$ is adopted in the model (Chang, 2004). The parameter $M$ (erosion constant) depends on the physical-chemical characteristics of bottom sediment. In the model simu- lation of Danshuei River estuarine system, a value of $1.2 \times 10^{-7} \mathrm{~g} / \mathrm{cm}^{2} / \mathrm{s}$ is used (Liu et al., 2002). The critical stress for deposition, $\tau_{D}$, depends mainly on the size of the floc, since bigger flocs generally have higher probability of remaining on the bed than smaller flocs. Nevertheless, previous work suggested that a constant value is a reasonable approximation. The value of $0.65 \mathrm{dyne} / \mathrm{cm}^{2}$ is used in the model simulation. Critical shear stress for erosion, $\tau_{E}$, is a function of the degree of compactnesss of bottom sediments measured by the dry density of the bottom sediments: ratio between the mass 

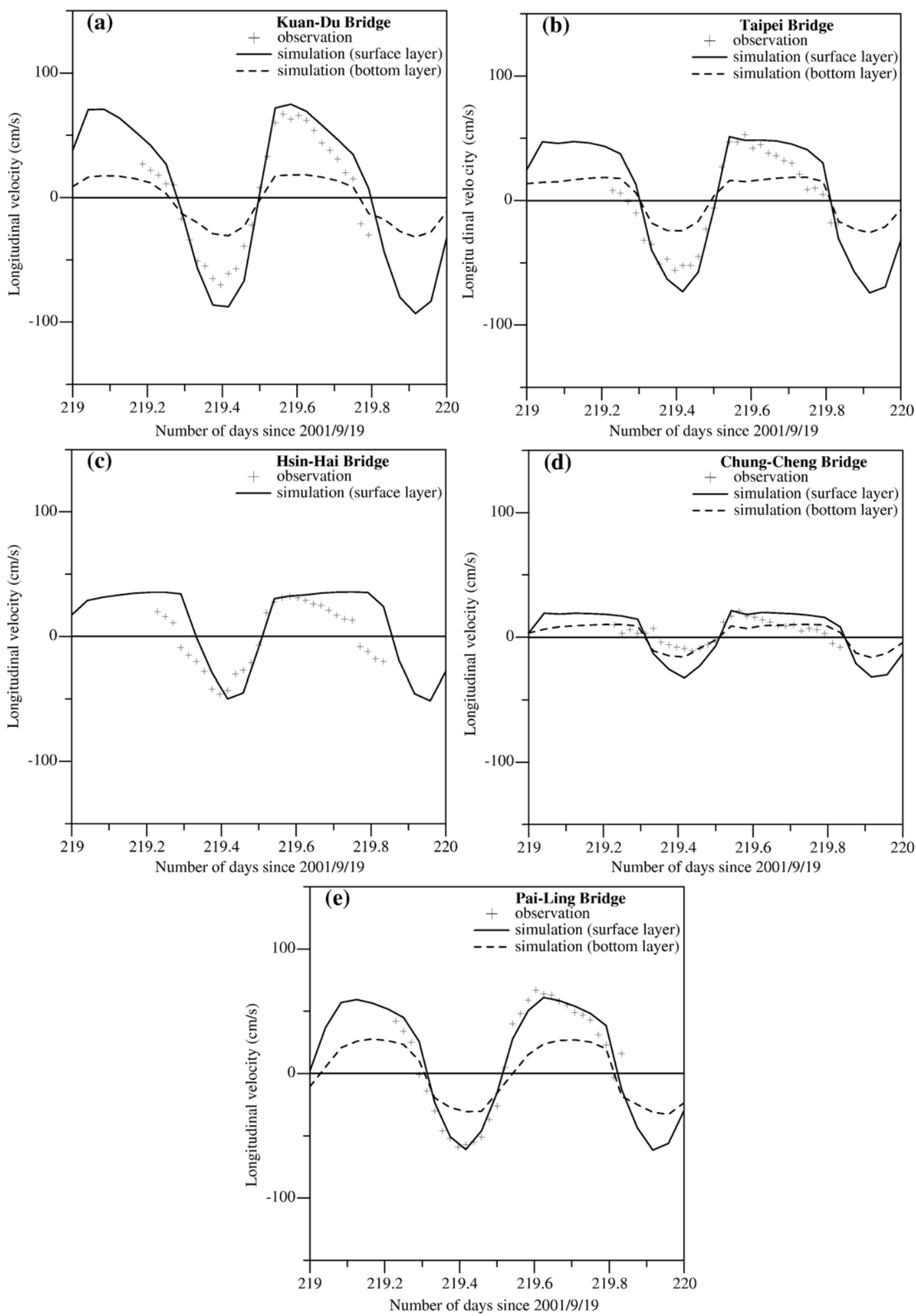

Fig. 4. Comparison of predicted and measured longitudinal velocity on April 26, 2002 at (a) Kuan-Du Bridge, (b) Taipei Bridge, (c)Hsin-Hai Bridge, (d) Chung-Cheng Bridge, and (e) Pai-Ling Bridge. 

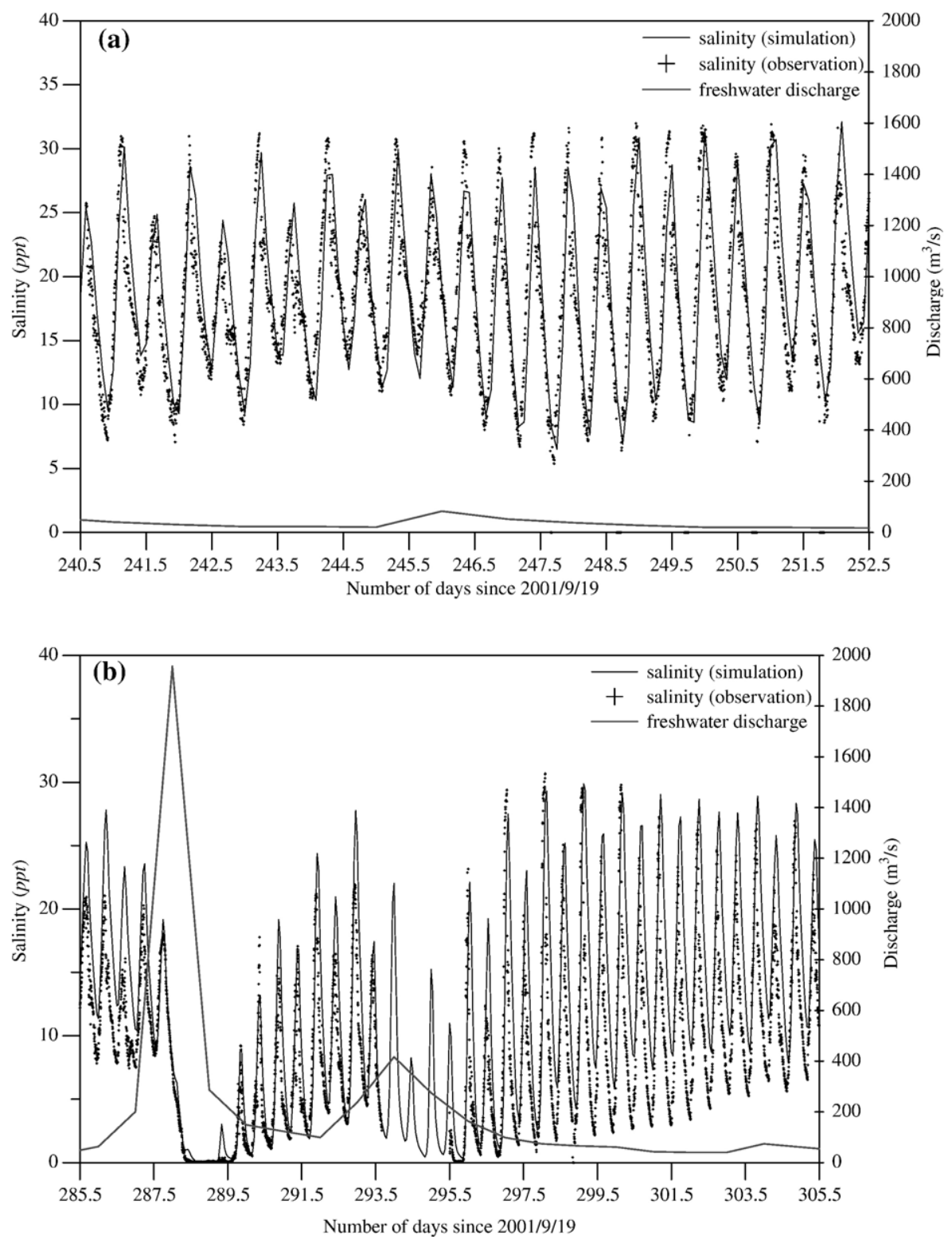

Fig. 5. Predicted and measured salinity time series at the Kuan-Du Bridge as a function of the number of days since September 19, 2001 (a) 240.5-252.5 days, (b) 285.5-305.5 days.

of sediment and its initial volume (Delo, 1988). The $\tau_{E}$ of $1.15 \mathrm{dyne} / \mathrm{cm}^{2}$ is adopted in the model simulation (Liu et al., 2002).

The numerical model predictions by the daily averages, minimum and maximum suspended sediment concentration (SSC) results were compared with the values obtained from field measurements and are depicted in Fig. 6. The field measurement presented in the figure includes high tide, low tide, and mean values. It is apparent that the field observations missed most of the peak concentrations predicted by the model. These predicted peak sediment concentrations are the results of storm induced high freshwater flow coming from upriver, while almost all of the data were collected under fair weather condition. Nevertheless, the results show reasonable agreement between the model predictions and field observations.

\subsection{Estimation of partition coefficient $\left(K_{d}\right)$}

The partition coefficient, $K_{d}$, determining the distribution of a heavy metal between adsorbed and dissolved 

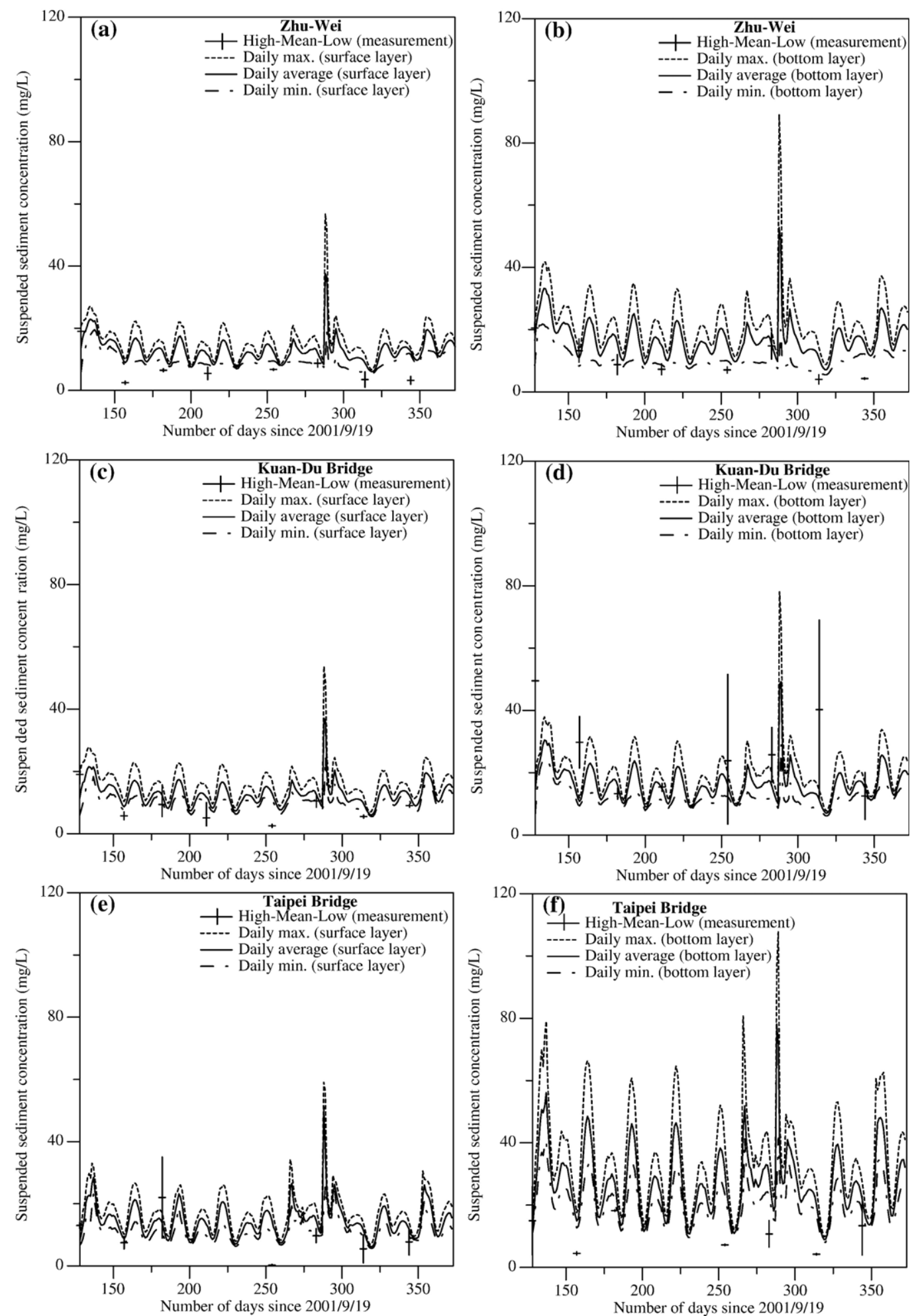

Fig. 6. Predicted and measured suspended sediment concentration (a) Zhu-Wei (surface layer), (b) Zhu-Wei (bottom layer), (c) Kuan-Du Bridge (surface layer), (d) Kuan-Du Bridge (bottom layer), (e) Taipei Bridge (surface layer), and (f) Taipei Bridge (bottom layer). 
fractions, depends on the physical and chemical characteristics of the suspended particles and ambient conditions, such as salinity, $\mathrm{pH}$, etc. Due to the complexity in determining the partition coefficient, a mean value for the partition coefficient has often been used in such applications. Turner and Millward (1994) used the $K_{d}$-salinity relationships predicted from the regression equations and compared with measured values in the Dee Estuary (north-east Wales). Shrestha and Orlob (1996) applied the $K_{d}$-suspended sediment concentration relationships to model total and dissolved nickel concentrations in the San Francisco Bay. Mwanuzi and Smedt (1999) estimated the $K_{d}$ related to the suspended sediment concentration in the Scheldt Estuary and Belgian coast area. Hartnett et al. (2006) postulated a function relationship between $K_{d}$ versus salinity in the Mersey Estuary, UK. In this study an exponential relationship with salinity and suspended sediment concentration was used as given by:

$\ln K_{d}=a \cdot(S)+b \cdot(m)+c$

where $a, b$ and $c$ are constants, $S$ is salinity, and $m$ represents the SSC. The values of the constants included in Eq. (7) were obtained from a regression analysis of field data provided by the National Center for Ocean Research, Taiwan (Jiann et al., 2005). Fig. 7 shows the regression results for the $K_{d}$, salinity and SSC data. The values of $a$, $b$, and $c$ were $0.102,0.019$ and 10.144 respectively, for a coefficient of determination of $R^{2}=0.70$.

\subsection{Heavy metal transport}

Modelling heavy metals in an estuary is dependent on accurate modelling of hydrodynamics, salinity and suspended sediment concentration as well developing a good understanding of the partition coefficient $\left(K_{d}\right)$. For model validation, the measured field data of copper provided by the National Center for Ocean Research (NCOR), Taiwan were used. The concentrations of copper at upstream boundaries and river mouth are set to $5 \mu \mathrm{g} / \mathrm{L}$ and $1 \mu \mathrm{g} / \mathrm{L}$, respectively. The simulation periods are the same as hydrodynamic and sediment calculations. The point source load of total copper at the HsinHai Bridge is specified as $250 \mathrm{~kg} /$ day. The comparisons of simulation results and field data of total, dissolved, and particulate copper concentrations along the Danshuei River mouth to Tahan Stream are presented in Figs. 8 and 9. The measured data include two sampling occasions on October 13, 2001 and January 24, 2002. The daily averages, maximum, and minimum of the model results were plotted in the figures. The results reveal that the model computed total and dissolved copper concentrations agree with the field observations, especially at the Hsin-Hai Bridge, where the very high total copper concentration, similar to those reported by EPA of Taiwan, was observed on October 13, 2001. The computed particulate copper concentration underestimates the measured value at the Hsin-Hai Bridge. NG et al. (1996) argued that the observed and modeled

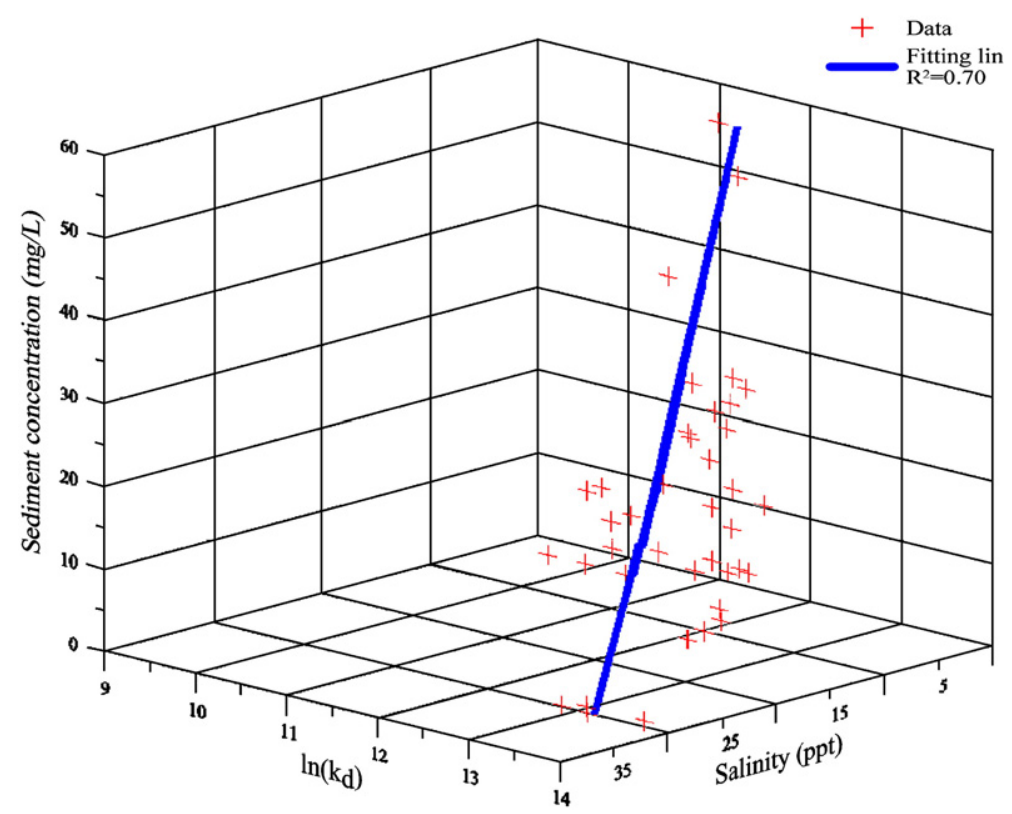

Fig. 7. Representation of the regression curve for the $K_{d}$, salinity and suspended sediment concentration data. 

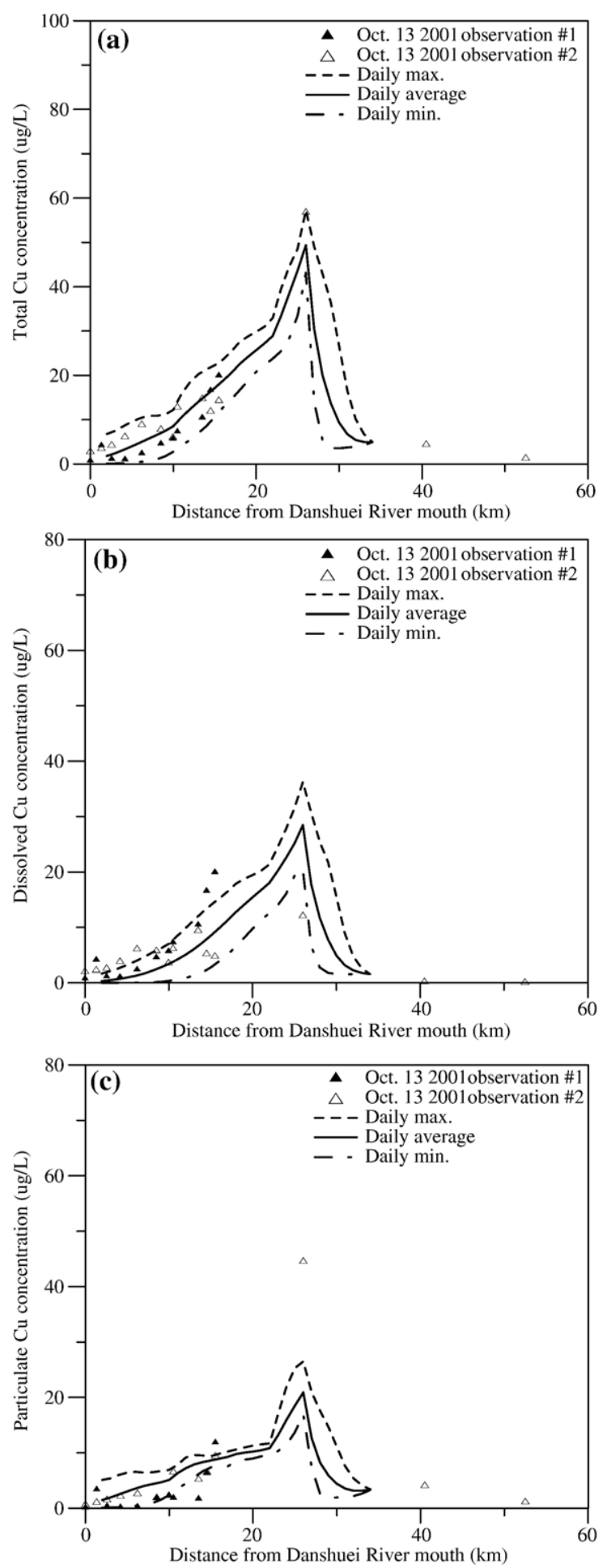

Fig. 8. Comparison of predicted and measured copper concentration in the Danshuei River-Tahan Stream on October 13, 2001 (a) total copper concentration, (b) dissolved copper concentration, (c) particulate copper concentration.
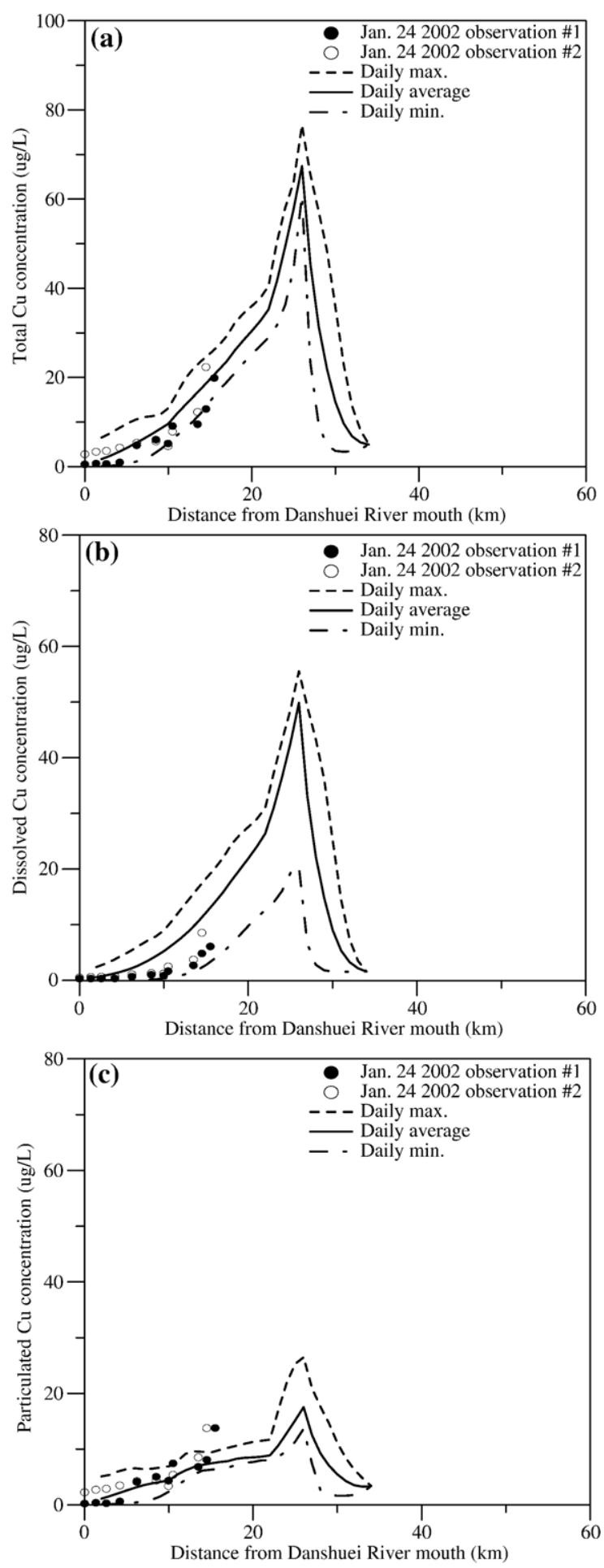

Fig. 9. Comparison of predicted and measured copper concentration in the Danshuei River-Tahan Stream on January 24, 2002 (a) total copper concentration, (b) dissolved copper concentration, (c) particulate copper concentration. 
concentrations of particulate heavy metal differ by an order of magnitude in the Humber Estuary, UK. This discrepancy is the result of the difference between the particulate metal associations that are modeled and measured. The laboratory analysis includes those particulate metals occluded within oxides and more refractory minerals which are unable to particulate in shortterm biogeochemical reactions. The argument seems to exist in the Danshuei River estuary, especially the huge garbage dump site near the Hsin-Hai Bridge.

\section{Model applications}

The calibrated and verified model was applied to simulate the Danshuei River estuarine system and to investigate the copper transport. The time series data of surface elevation at the Danshuei River mouth, collected by the Taiwan Water Resources Agency, were examined and harmonic analyses were performed. Nine principal constituents were identified, they are $M_{2}(12.42 \mathrm{~h}), S_{2}(12 \mathrm{~h}), N_{2}(12.9 \mathrm{~h}), K_{1}(23.93 \mathrm{~h}), S_{a}$ (8765.32h), $O_{1}(25.82 \mathrm{~h}), K_{2}(11.97 \mathrm{~h}), P_{1}(24.07 \mathrm{~h})$, and $M_{4}(6.21 \mathrm{~h})$. Amplitudes and phases of the constituents were specified to generate a time series of surface elevation as the downstream boundary condition for a oneyear (705 tidal cycles) model simulation run. The $Q_{75}$ discharges (the flow which is equaled or exceeded $75 \%$ of time) at the upstream boundaries of the three major tributaries were used. They are $8.15 \mathrm{~m}^{3} / \mathrm{s}, 20.2 \mathrm{~m}^{3} / \mathrm{s}$, and $3.61 \mathrm{~m}^{3} / \mathrm{s}$ for the Tahan Stream, Hsintien Stream, and Keelung River, respectively. Salinity at the Danshuei River mouth was set at 32 ppt under $Q_{75}$ flow condition.
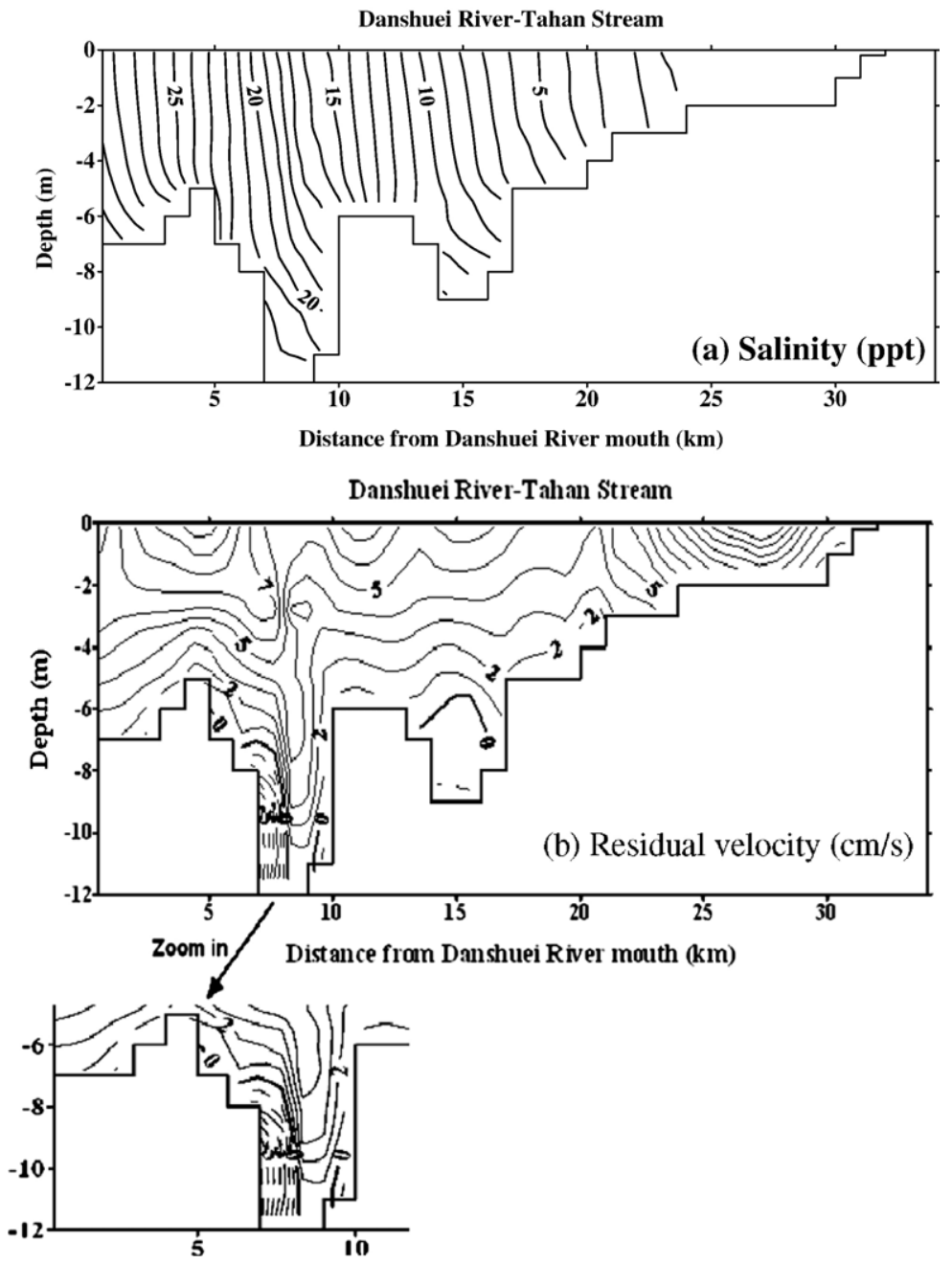

Fig. 10. Calculated distributions of (a) salinity, (b) residual velocity, (c) suspended sediment concentration, and (d) copper concentration averaged over 58 tidal cycles under $Q_{75}$ flow condition in the main stream of Danshuei River-Tahan Stream. 

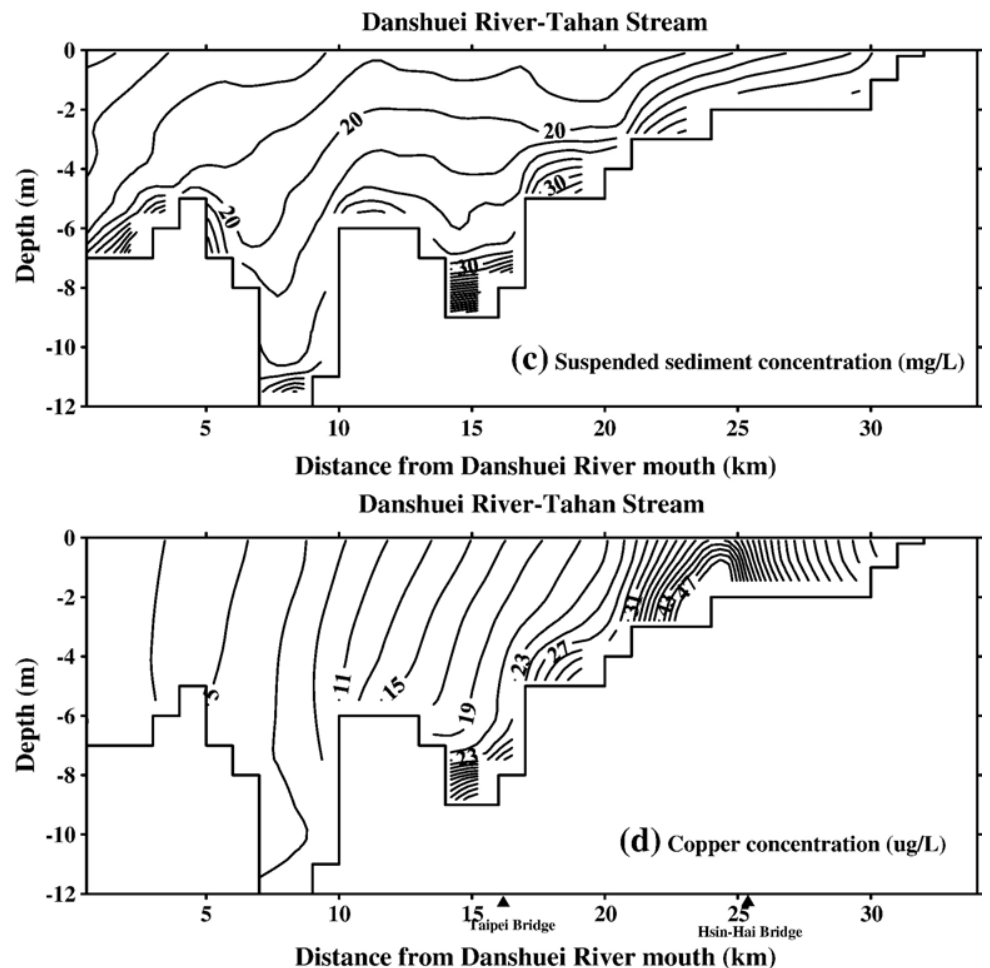

Fig. 10 (continued).

In the sediment transport model, the characteristic concentration of $10 \mathrm{mg} / \mathrm{L}$ was used for the boundary condition at the river mouth. The upriver boundaries are located at the limits of the tide in the three tributaries, and a constant concentration of $40 \mathrm{mg} / \mathrm{L}$ was imposed. In the heavy metal copper transport model, the total copper concentration of $1 \mu \mathrm{g} / \mathrm{L}$ was specified at the river mouth. At the upstream boundaries of three tributaries, constant concentration of $5 \mu \mathrm{g} / \mathrm{L}$ was imposed. The model was run for one-year duration (705 tidal cycles).

Fig. 10 presents the average salinity, residual current, suspended sediment concentration, and total copper concentration distributions over 2 spring-neap cycles (i.e., 58 tidal cycles) in the main stream of Danshuei RiverTahan Stream. Fig. 10(a) illustrates that the limits of salt intrusion are located at Hsin-Hai Bridge in Tahan Stream, about $24 \mathrm{~km}$ from the Danshuei River mouth. The extensive intrusion of saline water imposes a significant baroclinic forcing and induces a strong residual circulatory system in the estuary. Fig. 10(b) shows the tidally-averaged longitudinal velocity distributions. The positive current presents downriver flow and negative current directs to upriver flow. The strongest upriver bottom flow occurs in the deeper waters around the Kuan-Du Bridge and Taipei Bridge. The residual circulation in the estuary arises from the pressure gradient generated by the longitudinal salinity variation, a baroclinic forcing which increases with depth as well as the salinity gradient. The tidally-averaged sediment concentration distributions, averaged over 2 spring-neap cycles, are shown in Fig. 10(c). A local maximum concentration exists around the null point (i.e. the velocity is zero) in the Danshuei River-Tahan Stream.

Fig. 10(d) presents the tidally-averaged distribution of the total copper concentration. Due to the local point source pollutant, the highest total copper concentration is located around the Hsin-Hai Bridge. It also shows that a local maximum of total copper concentration occurred at the bottom layer, near the Taipei Bridge, probably because of the null point in residual circulation. The local maximum concentration of copper, which is attributed mostly to the particulate phase, is approximately half of that calculated for the region near the point source at Hsin-Hai Bridge. This fact has the important implication that heavy metals from upriver sources may accumulate in the lower reach of the Danshuei River estuary around the null point of estuarine circulation. The accumulation may be further enhanced by the relatively depressed topography of the river bed. 


\section{Conclusions}

A geochemical module based on the empiricallyderived partition coefficients, coupled to a laterally averaged, two-dimensional hydrodynamic model in the Danshuei River estuary, has formed the basis of a geochemical contaminant transport model. The model was validated with observed time series of water surface elevation, current, salinity, and suspended sediment concentration in 2001 and 2002. The calculated distributions of total, dissolved, and particulate copper concentrations along the Danshuei River-Tahan Stream compare with field measured data. The predicted results agreed well, generally, with the data for the barotropic and baroclinic flows, suspended sediment concentration, total and dissolved copper concentrations in the estuarine system. The model underpredicts the particulate copper concentration at the Hsin-Hai Bridge, where there is a garbage dump site, probably due to a lack of analytical techniques capable of determining an adsorbed component of particulate metals.

The validated model was then applied to investigate the tidally-averaged salinity distributions, residual circulation, suspended sediment concentration, and total copper concentration under low flow $\left(Q_{75}\right)$ condition. The most important aspect of estuarine circulation in the Dasnhuei River system is the gravitational circulation. The tidally-averaged circulation is characterized by the upriver movement of denser saline water in the lower layer and the downriver movement of fresher water in the upper layer. The circulation pattern is driven by the longitudinal gradient of salinity distribution. The residual circulation occurs in the deep channel near the Kuan-Du Bridge and the Taipei Bridge. Under $Q_{75}$ flow condition, the limits of salt intrusion are located near the Hsin-Hai Bridge in the Tahan Stream, $24 \mathrm{~km}$ from the river mouth. The tidally-averaged sediment distribution, averaged over 2 spring-neap tidal cycles, exhibits a local maximum concentration around the null point in the Danshuei River-Tahan Stream. The model requires a point source with a copper load of $250 \mathrm{~kg} /$ day to reproduce the persistent high copper concentration around the Hsin-Hai Bridge and the downriver decreasing concentration. The model predicts a rather high total copper concentration at the bottom layer near Taipei Bridge because of the null residual circulation there. It appears that heavy metals from upriver sources may accumulate at the null point of the estuarine circulation in the lower reach of the estuary. Further work is required to validate the model predictions for the hotspot of heavy metal contaminant. However, this study has shown that the numerical model applied herein has good potential for use in the simulation of contaminant cycling in an es- tuary with similar characteristics to the Danshuei River system.

\section{Acknowledgements}

The project under which this study is conduced is supported by National Science Council, Taiwan, under grant No. NSC 94-2211-E-239-011. The authors like to express their appreciation to the Taiwan Water Resources Agency, Environmental Protection Administration, and National Center for Ocean Research for providing the measured field data. Two anonymous reviewers are thanked for their constructive comments.

\section{References}

Adamo P, Dudka S, Wilson MJ, Mchardy WJ. Distribution of trace elements in soils from the Sudbury smelting area (Ontario, Canada). Water Air Soil Pollut 2002;137:95-116.

Birch G, Taylor S. Source of heavy metals of the Port Jackson estuary, Australia. Sci Total Environ 1999;227:123-38.

Blumberg AF. Numerical model of estuarine circulation. J Hydraul Eng Div ASCE 1977;103(HY3):295-310.

Bourg ACM. Trace metal adsorption modelling and particle-water interactions in estuarine environments. Cont Shelf Res 1987;7: 1319-32.

Chang ST. Field survey of water quality and suspended sediment in the Danshuei River estuary. Institute of Hydrological Sciences, National Central University; 2004. 96 pp.

Chen CW, Leva D, Olivieri A. Modeling the fate of copper discharged to San Francisco Bay. J Environ Eng ASCE 1996;122:924-34.

Delo EA. Estuarine muds manual. Report No. SR 164. Wallingford, UK: Hydraulic Research; 1988. 64 pp.

Dyer KR. Estuaries: a physical introduction. John Wiley \& Sons; 1997. $195 \mathrm{pp}$.

Fang TH. Partitioning and behavior of different forms of phosphorus in the Tanshui Estuary and one of its tributaries, northern Taiwan. Estuar Coast Shelf Sci 2000;50:689-701.

Fang GC, Chang CN, Wu YS, Wang V, Fu PCP, Yang DG, et al. The study of fine and coarse particles, an metallic elements for the daytime and night-time in a suburban area of central Taiwan, Taichung. Chemosphere 2000;41:639-44.

Hartnett M, Lin BL, Jones PD, Berry A. Modelling the fate and transport of nickel in the Mersey Estuary. J Environ Sci Health, Part A 2006;41:825-47.

Hayter EJ, Mehta AJ. Modelling cohesive sediment transport in estuarine waters. Appl Math Model 1986;10:294-303.

He M, Wang Z, Tang H. Modeling the ecological impact of heavy metals on aquatic ecosystems: a framework for the development of an ecological model. Sci Total Environ 2001;266:291-8.

Hsu MH, Kuo AY, Kuo JT, Liu WC. Procedure to calibrate and verify numerical models of estuarine hydrodynamics. J Hydraul Eng ASCE 1999;125:166-82.

Hsu MH, Kuo AY, Liu WC, Wu JT, Hwang JS. Hydrodynamics, water quality, and ecosystem modeling in the tidal Danshuei River estuarine system. Taiwan: Report to National Science Council; 2003.

Huang KM, Lin S. Consequences and implication of heavy metal spatial variations in sediments of the Keelung River drainage basin, Taiwan. Chemosphere 2003;53:1113-21. 
Jeng WL, Han BC. Sedimentary coprostanol in Kaohsiung harbor and the Tanshui Estuary, Taiwan. Mar Pollut Bull 1994;28:494-9.

Jiann JT, Wen LS, Santschi PH. Trace metal $(\mathrm{Cd}, \mathrm{Cu}, \mathrm{Ni}$ and $\mathrm{Pb})$ partitioning, affinities and removal in the Danshuei River estuary, a macro-tidal, temporally anoxic estuary in Taiwan. Mar Chem 2005;96:293-313.

Krone RB. Flume studies of the transport in estuarine shoaling processes. Final Report, Hydraulic Engineering Laboratory and Sanitary Engineering Research Laboratory. Berkeley: University of California; 1962.

Lin S, Hsieh IJ, Huang KM, Wang CH. Influence of the Yangtz River and grain size on the spatial variations of heavy metals and organic carbon in the East China Sea continental shelf sediment. Chem Geol 2002;182:377-94.

Liu WC, Hsu MH, Kuo AY. Investigation of long-term transport in Tanshui River estuary, Taiwan. J Waterw Port Coast Ocean Eng ASCE 2001a;127:61-71.

Liu WC, Hsu MH, Kuo AY, Kuo JT. The influence of river discharge on salinity intrusion in the Tanshui estuary, Taiwan. J Coast Res 2001b;17:544-52.

Liu WC, Hsu MH, Kuo JT. Modelling of hydrodynamics and cohesive sediment transport in Tanshui River estuarine system, Taiwan. Mar Pollut Bull 2002;44:1076-88.

Liu WC, Hsu MH, Wu CR, Wang CF, Kuo AY. Modeling salt water intrusion in Tanshui River estuarine system-case-study contrasting now and then. J Hydraul Eng ASCE 2004;130:849-59.

Liu WC, Chen WB, Cheng RT, Hsu MH, Kuo AY. Modeling the influence of river discharge on salt intrusion and residual circulation in Danshuei River estuary, Taiwan. Cont Shelf Res 2007;27:900-21.

Lung WS, Light RN. Modelling copper removal in wetland ecosystems. Ecol Model 1996;93:89-100.

Mwanuzi F, De Smedt F. Heavy metal distribution model under estuarine mixing. Hydrol Process 1999;13:789-804.

$\mathrm{Ng}$ B, Turner A, Tyler AO, Falconer RA, Millward GE. Modelling contaminant geochemistry in estuaries. Water Res 1996;30:3-74.

Odd NVM, Owen MW. A two-layer model of mud transport in the Tames estuary. Proceedings of Institute of Civil Engineers. London: Thomas Telford; 1972. p. 195-202.
Pritchard DW. The movement and mixing of contaminants in tidal estuaries. In: Pearson EA, editor. Waste Disposal in Marine Environment. Pergamon Press; 1960.

Shrestha PL, Orlob GT. Multiphase distribution of cohesive sediments and heavy metals in estuarine systems. J Environ Eng ASCE 1996;122: $730-40$.

Partheniades E. Erosion and deposition of cohesive soils. J Hydraul Eng Div ASCE 1965;91(HY1):105-39.

Turner A, Millward GE. The partitioning of trace metals in a macrotidal estuary: Implications for contaminant transport model. Estuar Coast Shelf Sci 1994;39:45-58.

Turner A, Millward GE. Suspended particles: their role in estuarine biogeochemical cycles. Estuar Coast Shelf Sci 2002;55:857-83.

Turner A, Millward GE, Le Roux SM. Sediment-water partitioning of inorganic mercury in estuaries. Environ Sci Technol 2001;35: 4648-54.

Van Maldegem DC, Mulder HPJ, Langerak A. A cohesive sediment balance for the Scheldt estuary. Neth J Aquat Ecol 1993;27: 247-56.

Wang CF, Hsu MH, Liu WC, Hwang JS, Wu JT, Kuo AY. Simulation of water quality and plankton dynamics in the Danshuei River estuary, Taiwan. J Environ Sci Health Part A 2007;42:933-53.

Windom HL, Schropp SJ, Calder FD, Ryan JD, Smith Jr RG, Burney LC, et al. Natural trace metal concentrations in estuarine and coastal marine sediments of the southeastern United States. Environ Sci Technol 1989;23:314-20.

Woitke P, Wellmitz J, Helm D, Kube P, Lepom P, Litheraty P. Analysis and assessment of heavy metal pollution in suspended solids and sediments of the river Danube. Chemosphere 2003;51:633-42.

$\mathrm{Wu}$ SC. The treatment of domestic sewage by soil. Taiwan EPA Report: EPA 86-E3G1-09-02; 1997 (in Chinese).

Wu Y, Falconer R, Lin B. Modelling trace metal concentration distributions in estuarine waters. Estuar Coast Shelf Sci 2005;64: 699-709.

Zagar D, Knap A, Warwick JJ, Rajar R, Hovat M, Cetina M. Modelling of mercury transport and transformation processes in the Idrijca and Soca river system. Sci Total Environ 2006;368(1): 149-63. 